\title{
The role of intolerance of uncertainty in the relationship between daily search for and presence of meaning in life
}

\author{
Jessica L. Morse $\cdot$ Mark A. Prince $\cdot$ Michael F. Steger
}

\begin{abstract}
People who are highly intolerant of uncertainty have a propensity to fear the unknown, which influences perceptions and desires for control and predictability (Carleton, 2016). Processes related to searching for and maintaining meaning might deviate based on intolerance of uncertainty as meaning-making can be spurred by breakdowns in one's sense of understanding or predictability (Park, 2010). The current study was designed to examine within-person relationships between daily search for and presence of meaning, while investigating how people's intolerance of uncertainty (IU) influences the search-presence relationship. During a three-week daily diary study, results showed that daily search significantly predicted same-day presence and presence the following day. IU significantly moderated the effects of search on presence such that people who were highly intolerant of uncertainty experienced less presence when they engaged in searching than low IU participants. Results suggest researchers should consider the potential consequences of IU in limiting the development of a vital well-being resource, presence of meaning.
\end{abstract}

Keywords: meaning; intolerance of uncertainty; search for meaning; personality processes; daily diary; meaning in life

\section{Introduction}

1.1 The role of intolerance of uncertainty in the relationship between daily search for and presence of meaning in life

Meaning in life is a core component of people's well-being, and the accelerating pace of research on meaning in life demonstrates that it aids people in coping with the challenges and uncertainties of daily life. Mostly, researchers have focused on the idea that meaning in life can be a stable resource, which some refer to as presence of meaning (Steger et al., 2006), consisting of our cognitive understanding of ourselves and our lives, our sense of purpose, and the feeling that our lives matter (Martela \& Steger, 2016). A subset of research has considered how people accrue meaning through searching for meaning. Scholars define the search for meaning as "the strength, intensity, and activity of people's desire and efforts to establish and/or augment their understanding of the meaning, significance, and purpose of their lives" (Steger et al., 2008, p. 200). Where research on presence of meaning is abundant and consistent, research on search for meaning is less common and less consistent, often seeming to tell a subtle, complex story in which the context surrounding the search determines what influence, if any, search for meaning contributes to presence of meaning and well-being (e.g., Cohen \& Cairns, 2012). Both search for and presence of meaning have been studied primarily on the trait rather than state level. However, one of the foundational existential thinkers, Frankl (1963), envisioned both searching

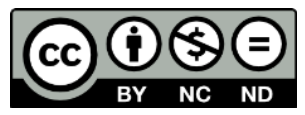

Copyright belongs to the author(s) www.internationaljournalofwellbeing.org 
for and experiencing meaning to be fundamental human motivations that ebb and flow daily, even hourly. Accordingly, this study was designed to look more closely at state levels of meaning, by investigating daily fluctuations in search for and presence of meaning in the context of a potential dispositional moderator of the relationship to explore nuances in the relationship between presence of and search for meaning.

\subsection{Relationship between presence of and search for meaning in life}

In most research, presence of and search for meaning are conceived of as stable individual differences, measured using global scales focusing respondents' attention to life in general. Those who score high on presence of meaning also report psychological health (e.g., Ryff, 1989), life satisfaction (Zika \& Chamberlain, 1992), happiness (Peterson et al., 2005), positive affect (King et al., 2006), and low levels of psychopathology (e.g. Ryff, 1989). Links between search for meaning and psychological outcomes are less consistent. Frankl (1963) specified searching for meaning as a healthy, natural motivational force that fuels people to better understand their experiences, yet empirical research presents a mixed view. Much of the empirical research within US samples suggests searching for meaning relates to dysfunction (e.g., Steger et al., 2006); at the same time, search for meaning is positively correlated with otherwise desirable traits, such as curiosity and a tendency to become absorbed in one's experiences (e.g., Kashdan \& Steger, 2007). Steger and colleagues (2008) proposed that the implications of searching for meaning might depend on individuals' reasons for searching, their extant sense of meaning in life, and other personality characteristics. In brief, searching for meaning may be indicative of healthy growth for some individuals, whereas for others, searching may be a sign of distress. Perhaps if people searching for meaning feel certain that they are on a promising path, they are more likely to experience well-being.

The relationship between presence of and search for meaning also appears mixed. In an unpublished systematic review of meaning in life studies in US adult samples, Steger and colleagues (2017) found search for and presence of meaning correlated non-significantly at small, negative values across most studies. Thus, when people feel that their lives are meaningful, they are less likely to search for meaning, and when they report searching for meaning, they are less likely to report having high presence of meaning at that time. Although high levels of search and presence are not typically positively correlated in US adult samples, Park and colleagues (2010) found that when individuals report high levels of search and presence, search is associated with positive well-being outcomes rather than distress. To add to the complexity, several researchers have reported small, positive correlations between search and presence in adolescents and young adult samples (e.g., Bailey \& Phillips, 2016; Dik et al., 2012), suggesting searching for meaning may be developmentally appropriate for adolescents and young adults even when they experience their lives as meaningful.

Across all ages, theorists assert that people have an inherent need for meaning and strive to maintain their sense of meaning (Heine et al., 2006; Park, 2010). However, people experience events and situations that challenge their understanding of themselves and the world around them. Heine and colleagues (2006; Meaning Maintenance Model) suggest that when people experience something that threatens their expectations of how things are supposed to be, they compensate by trying to regain a sense of meaning. When people experience a violation to their meaning framework, they may experience distress and recognize a need to resolve the incongruence by reaffirming alternative domains of meaning (Heine et al., 2006) or by seeking new understanding(s) (Park, 2010). Steger and colleagues' (2008) framework elucidates the processes involved in the relationship between search for and presence of meaning in their 
presence-to-search and search-to-presence conceptual models. The presence-to-search model identifies deficits in presence of meaning as igniting searching for meaning, such that when people experience decreases in presence, they search to restore their sense of meaning (Steger et al., 2008). Additionally, when people report higher presence of meaning they report less searching (Newman et al., 2017). Steger and colleagues (2008) also outline a different mechanism through which people initiate searching for meaning to generate greater presence of meaning (search-to-presence). In other words, people are driven to search for meaning, and when they do so, they find and experience more meaning. In their study, Steger and colleagues' (2008) results supported the presence-to-search conceptual model. Steger and colleagues' (2008) study was cross-sectional and did not explore the dynamics of presence and search over time.

Newman and colleagues (2017) examined relations between daily presence, search, and wellbeing. They found that daily search positively related to same day presence and well-being and that higher levels of search on one day led to greater presence the next (Newman et al., 2017). In other words, someone who is a "searcher" might look quite different in terms of well-being and affect than someone who is "searching" for meaning on a particular day. At the daily level, searching appears to relate to both positive and negative indicators of functioning. Results of daily studies indicate that daily searching increases when meaning is threatened (Park et al., 2017) and is associated with greater perceived stress (Machell et al., 2017); however, daily searching is also significantly correlated with daily curiosity (Garrosa et al., 2016), well-being and presence of meaning (Newman et al., 2017).

These results from daily experience methods align with the search-to-presence model, and further suggest that searching for meaning on a given day may function differently from searching for meaning at the trait-level. Examining search and presence at the daily level provide a more nuanced assessment of their relationship and indicate that search for meaning sometimes is positively associated with wellbeing and presence of meaning. However, extant research does not explain why daily searching relates to such varied outcomes. We hypothesize that an underlying personality factor, intolerance of uncertainty, may explain why some people engage in daily searching and report more presence of meaning and higher levels of well-being whereas others engage in daily searching and report emotional exhaustion and distress.

\subsection{The present study: MIL and uncertainty}

The current study was conducted to clarify the dynamic between daily search for and presence of meaning by further examining the presence-to-search and search-to-presence conceptual models and by including a novel trait-level moderator in the analyses. Beginning with the observation that sometimes searching for meaning is experienced as positive, but typically it is not, we explore the possibility that searching itself may be more than one process, or more specifically, that some people are prone to confronting the process of searching for meaning with distress. Perhaps the cognitive attributions people generate when they recognize a need to make sense of an experience influence their reactions to and engagement in the search process. In other words, the extent to which people regard searching for meaning to be an ambiguous process with an uncertain or unknowable outcome paired with their perceived ability to manage that uncertainty will influence the search-presence relationship. Where people high in curiosity may seek out or approach new experiences excitedly, those high in IU tend to avoid and experience distress when confronted with ambiguity and uncertainty.

IU describes discomfort and difficulty with tolerating the unknowable, even as the unknowable may be inherent in searching for meaning. IU is defined as "an individual's dispositional incapacity to endure the aversive response triggered by the perceived absence of 
salient, key, or sufficient information, and sustained by the associated perception of uncertainty" (Carleton, 2016; p. 31). Because individuals high in IU perceive uncertainty as threatening, they may be motivated to seek information in efforts to re-establish certainty when it is lost so as to regain a sense of control and predictability. Accordingly, research suggests people who are highly intolerant of uncertainty are more likely than those low in IU to endorse a need for cognitive closure, a preference for order, and close-mindedness (e.g., Berenbaum et al., 2008), which may perpetuate a desire to foreclose, or quickly come to a conclusion, rather than explore and entertain many possibilities. However, research also indicates that when high IU individuals experience uncertainty, they experience anxiety and worry that perpetuates avoidance of the experience of uncertainty (Shihata et al., 2016).

Recent research on the conceptual nature of IU postulates two dimensions within the construct of IU: prospective and inhibitory IU. Prospective IU refers to the desire to know what the future holds. People who are high in prospective IU tend to engage in appraising potential threats related to future uncertainty, whereas inhibitory IU reflects behavioral responses like avoidance of uncertainty (Berenbaum et al., 2008; Carleton et al., 2007; Shihata et al., 2016). Individuals who are high in prospective IU strongly endorse items like, "I always want to know what the future has in store for me". (Carleton et al., 2007, pp. 117). Inhibitory IU is reflected in high endorsement of items like, "When it is time to act, uncertainty paralyzes me" (Carleton, 2012). Birrell and colleagues (2011) propose these dimensions may function differently such that individuals high in prospective IU may engage in approach behaviors to stave off uncertainty whereas individuals high in inhibitory IU may engage in avoidance behaviors to reduce their exposure to uncertainty. Although these two facets may represent different components of IU, research suggests inhibitory and prospective dimensions are strongly correlated (e.g., Fourtounas \& Thomas, 2016). In the context of searching for meaning, people high in prospective IU may actively seek to quickly resolve uncertainty and make meaning of an experience, whereas people high in inhibitory IU may avoid engaging with uncertainty, precluding searching for meaning.

Taking a step back, we suggest searching for meaning requires a willingness to experience uncertainty, to enter into the "unknown", whether that might be the future, a potential outcome, or the meaning of one's life. Searching for meaning involves experiencing uncertainty as one seeks to make sense of new information or take on new opportunities. If people find uncertainty too intolerable, they may not engage in searching for meaning at all (inhibitory IU), may engage in searching for meaning in a cursory manner directed at finding certainty quickly, perhaps by reaffirming alternative meaning domains (e.g., Heine et al., 2006) so as to reduce discomfort with uncertainty (prospective IU), and/or may only engage in searching when presence of meaning levels are high. Generally, people who are highly intolerant of uncertainty may avoid, or endure only under duress, experiences that provoke a sense of not knowing, and such experiences may motivate them to quickly assuage their distress or avoid it.

Searching for meaning may serve the function of reducing distress associated with uncertainty among those high in IU. Meaning is a tool for imposing a sense of stability, thus people innately seek to maintain meaning so that the world makes sense (e.g., Heine et al., 2006; Park, 2010). In attempting to maintain meaning, people may seek to foster meaning at concrete, specific levels (e.g., walking to work = an exercise in moving one's legs in sequence) or at broad, global levels (e.g., walking to work = an opportunity to pursue one's purpose) or somewhere in between (Baumeister \& Vohs, 2002; Park \& Folkman, 1997). Baumeister and colleagues (2002) suggest that people experience greater satisfaction and meaning when they are engaged in high- 
level, global meaning pursuits; however, people tend to shift to concrete levels of making meaning when they feel overwhelmed by their experience.

Theoretically, people high in IU are more likely to engage in concrete meaning-making to derive a sense of quick certainty, whereas people low in IU might be able to engage in broader, more "meaningful" searching due to their ability to tolerate not knowing. Or, as described previously, individuals high in IU may recruit alternative, unaffected meaning frameworks to regain a sense of meaning, essentially bypassing any searching or grappling with the unknown (MMM; Heine et al., 2006) Thus, people who are highly intolerant of uncertainty but who have multiple and/or robust meaning frameworks may be less likely to report searching for meaning when presence of meaning is low because they can employ alternative meaning frameworks to rebuild meaning, avoiding the distress associated with searching. In contrast, high IU people who lack existing meaning frameworks or who find their existing meaning frameworks unable to restore meaning may be more likely to experience distress as they try to make sense of new information and find new meaning. Overall, when high IU people search for meaning, their search might result in less "meaningful" meaning such that, in their efforts to assuage the discomfort of not knowing, they quickly grasp to concrete or existing meaning frameworks to redevelop a stable meaning framework as a resource for safety. The resulting sense of meaning may lack the durability of a meaning framework built on more thoroughly considered grounds.

Theoretical perspectives of meaning and uncertainty suggest that IU likely shapes whether and how people engage in searching for meaning and finding meaning. Yet, there is little empirical evidence to elucidate the exact role of IU in meaning-making. Thus, our hypotheses capture possible variations in the presence-search relationship, with an emphasis on the likelihood of IU as a disruptor in meaning-making processes due to the uncertainty inherent in searching for meaning.

\subsection{Hypotheses}

Based on the similar daily method used by Newman and colleagues (2017), we hypothesize that results of the relationship between daily presence of and search for meaning will support the search-to-presence conceptual model. However, due to limited research, both competing conceptual models will be tested. Further, the present study seeks to test IU as a moderator of the relationship between daily presence and search.

\subsubsection{Search-to-presence model}

Hypothesis 1a. Daily search for meaning will predict higher presence of meaning that same day.

Hypothesis $2 a$. IU will moderate the relation between daily search-presence such that low IU individuals will experience more benefit from searching (in producing presence of meaning) than high IU individuals. In other words, high IU individuals will experience distress that precludes their full engagement in and benefit from searching. Thus, the slope between search and presence will be steeper for low IU individuals and flatter for high IU individuals.

\subsubsection{Presence-to-search model}

Hypothesis $1 b$. Daily presence of meaning will negatively predict search for meaning that same day. In other words, lower levels of presence will predict higher levels of search.

Hypothesis $2 b$. IU will moderate the relation between daily presence-search such that high IU individuals engage in significantly less searching than low IU individuals because high presence will satisfy the meaning needs of high IU individuals, thus they will not experience a need to 
engage in a potentially distressing, uncertainty-provoking process, like searching. Thus, the slope between presence and search will be steeper for low IU individuals and flatter for high IU individuals.

\subsubsection{Lagged analyses}

To further examine directionality, lagged analyses were conducted to test the following hypotheses.

Hypothesis $3 a$. IU will moderate the relation between searching for meaning the day before and presence of meaning the following day, while controlling for search, such that low IU individuals will experience more benefit from searching the day before (in producing presence of meaning) than high IU individuals. In other words, it is likely that high IU individuals will experience distress that will preclude their full engagement in and benefit from searching. Thus, the slope between search the day before and presence will be steeper for low IU individuals and flatter for high IU individuals.

Hypothesis $3 b$. IU will moderate the relation between presence the day before and search the following day, while controlling for presence, such that high IU individuals engage in significantly less searching than low IU individuals because high presence on the day prior will satisfy the meaning needs of high IU individuals, and thus they will experience minimal need to engage in a potentially distressing, uncertainty-provoking process, like searching for meaning. Thus, the slope between presence the day before and search will be steeper for low IU individuals and flatter for high IU individuals.

\section{Method}

\subsection{Participants and procedure}

Sixty-six undergraduate students ( 49 women, 17 men; $M_{a g e}=19.03, S D_{a g e}=2.65$ ) in the psychology research pool at Colorado State University took part in this study. Ethical approval for the current study was provided by the Social, Behavioral, \& Education Research section of the Institutional Review Board at Colorado State University. The majority of participants identified as Caucasian (76\%), 6\% African-American, 3\% East Asian, 12\% Hispanic-American/Latino, and 6\% Multiracial/Other. Prior to attending a training session, participants were required to complete an initial battery of surveys, including the trait measure included in this study. During the training session, participants created usernames and learned how to log in and complete daily surveys. They received written instructions with their username, password, and the website to $\log$ in to complete daily surveys. Participants were instructed to complete a daily survey each day for the following 21 days between $9 \mathrm{pm}$ and 5am each night. Participants received reminder emails every 3 days. Survey responses were anonymized prior to data analysis.

\subsection{Trait measures}

Participants completed the Intolerance of Uncertainty Scale- Short Form (IUS-12; Carleton et al., 2007). Responses to twelve items were given on a scale of 1 to 5 ( $1=$ not at all characteristic of me, $5=$ entirely characteristic of me). Examples of items include, "Unforeseen events upset me greatly" and "I always want to know what the future has in store for me".

\subsection{Daily measures}

Daily measures of presence of meaning and search for meaning included items used in previous daily studies on a scale of 1-7 (1= not at all, 7= very much) (Kashdan \& Nezlek, 2012; Kashdan \& 
Steger, 2007). The daily presence scale included the items "How meaningful did you feel your life was today?" and "How much did you feel your life had purpose today?" The daily search scale included the following items: "How much were you searching for meaning in your life today?" and "How much were you looking to find your life's purpose today?".

\subsection{Analysis plan}

Based on the nature of the research question and the hierarchical structure of the data, moderated multilevel structural equation model (MSEM) was identified as the appropriate analytic model. Analyses were conducted using Mplus 7.4 (Muthén \& Muthén, 1998-2012). Search for meaning, presence of meaning, and IU were treated as continuous and normally distributed. Assumptions related to normality of data were tested and satisfied. Search and presence were measured at the daily level and days were nested within persons. IU was measured once at baseline for each individual.

All models were run as random effects models, which are commonly used to examine crosslevel interactions (Walker et al., 2013). Thus, intercepts and slopes were free to vary across participants. Bayesian estimation was utilized, which allows for individual level variability in the intercepts and slopes and results in estimated confidence intervals, Bayesian Credible Intervals, rather than point estimates for assessing significance of effects (e.g., van de Schoot et al., 2014). Due to the nature of the random models, no traditional model fit indices are available. Additionally, raw scores were not centered as Preacher and colleagues (2016) note that grandmean centering or using raw scores does not affect results in this type of model.

To test hypothesis 1a (Search-Presence), the random slope of the within-subjects effect of daily search was used to predict daily presence. To test hypothesis $1 \mathrm{~b}$ (Presence-Search), the random slope of the within-subjects effect of daily presence predicted daily search. To test hypothesis $2 \mathrm{a}$ and $2 \mathrm{~b}$ for Search-Presence and Presence-Search, a 2 X (1-1) moderation multilevel SEM was used (Preacher et al., 2010). The predictor (Search or Presence) and outcome (Presence or Search) were measured daily. The moderator (IU) was measured once at the baseline time point. All variables were incorporated into the MSEM as latent variables.

Hypotheses 2a, 2b, 3a and 3b were tested using the Random Coefficient Prediction (RCP) Method with Bayesian Credible Intervals (Preacher et al., 2016). With the RCP method, a latent variable for the random slope is calculated. RCP methodology allows the slope variable to vary as a function of the predictors while minimizing the slope's residual variance (Preacher et al., 2016). Specifying between and within level effects splits the between and within level variances such that they are not conflated, with the result that the within-level slope has only within-level variance and the between-level moderator has only between-level variance (Preacher et al., 2016). Moderation is then tested by examining if the moderator significantly predicts the random slope. RCP is especially useful for testing moderation in cross-level interactions (e.g., between-persons IU and within-persons SM and PM). The calculation of Bayesian Credible intervals, as opposed to point estimates of significance, provides a more robust test of statistical significance because repeated sampling of the data results in accurate estimation of asymmetrical confidence intervals that reflect that true distribution of the non-normal products of regression coefficients. Further, Bayesian estimation can be appropriately utilized with hierarchical data (Muthen \& Asparouhov, 2003). 


\section{Results}

\subsection{Descriptive statistics}

A total of 1,134 entries were collected, and 202 entries were missing or eliminated because the participant responded outside of the allocated response time, resulting in $15 \%$ missing data. Data was missing at random and this percentage of missing data is common in daily diary studies (e.g., Singer \& Willett, 2003). Although the sample size may appear small, within-subjects designs substantially increase power (e.g., Starr \& Davila, 2012) and MSEM controls for the nonindependence of nested effects and handles missing data well. The mean number of days completed was $16.94(\mathrm{SD}=3.57)$. The mean of IU was $29.53(S D=8.68$, Skew $=.24$, Kurtosis $=-$ .77 , Cronbach's alpha $=.90)$. The mean of the prospective anxiety subscale of the IUS-12 was 18.96 $(S D=5.15$, Skew $=.12$, Kurtosis $=-.74$, Cronbach's alpha $=.85)$. The mean of the inhibitory anxiety subscale of the IUS-12 was $10.74(S D=4.29$, Skew $=.59$, Kurtosis $=-.24$, Cronbach's alpha $=.88)$. The mean of daily presence was $5.19(S D=1.57$, Skew $=-.67 .$, Kurtosis $=-.25$, Cronbach's alpha $=)$ and mean daily search was $17.31(S D=8.68$, Skew $=-.10$, Kurtosis $=-.95$, Cronbach's alpha $=)$. IU was negatively correlated with search $(r=-.018, n s)$ and presence $(r=-.30, p<.05)$. At the daily level, presence and search were positively, significantly correlated $(r=.24, p<.05)$. At the trait level, presence and search were negatively correlated $(r=-.12, n s)$.

\subsection{Search-presence model (see Table 1)}

\subsubsection{Within-person effect of search on presence}

The random slope of daily search predicting daily presence was positive and statistically significant (Ssearch-Presence $=0.24$, Posterior SE $=.060$, Bayesian CI [.10, .35]), which is interpreted such that a 1-unit increase in daily search for meaning was associated with a .24 increase in presence of meaning.

Table 1. 2 X (1-1) RCP method of IUS X (Search-Presence) and IUS X (Search_1-Presence) Moderated MSEM

\begin{tabular}{|c|c|c|c|c|c|c|c|c|c|c|c|c|c|}
\hline \multicolumn{7}{|c|}{ Search-Presence of meaning } & \multicolumn{7}{|c|}{ Search_1 - Presence of meaning } \\
\hline \multirow[b]{2}{*}{$\begin{array}{l}\text { Within } \\
\text { Level }\end{array}$} & \multirow[b]{2}{*}{ Estimate } & \multirow[b]{2}{*}{$S D$} & \multirow[b]{2}{*}{$p$} & \multicolumn{2}{|c|}{ 95\% C.I. } & \multirow[b]{2}{*}{ Sig. } & \multirow[b]{2}{*}{$\begin{array}{l}\text { Within } \\
\text { Level }\end{array}$} & \multirow[b]{2}{*}{ Estimate } & \multirow[b]{2}{*}{$S D$} & \multicolumn{4}{|c|}{ 95\% C.I. } \\
\hline & & & & $\begin{array}{l}\text { Lower } \\
2.5 \%\end{array}$ & $\begin{array}{l}\text { Upper } \\
2.5 \%\end{array}$ & & & & & $p$ & $\begin{array}{l}\text { Lower } \\
2.5 \%\end{array}$ & $\begin{array}{l}\text { Upper } \\
2.5 \%\end{array}$ & Sig. \\
\hline Intercept & 3.70 & .097 & $<.001$ & 3.48 & 3.89 & * & Intercept & 3.34 & .17 & $<.001$ & 3.00 & 3.61 & * \\
\hline $\begin{array}{l}\text { Residual } \\
\text { Variance }\end{array}$ & .72 & .034 & $<.001$ & .66 & .79 & * & $\begin{array}{l}\text { Residual } \\
\text { Variance }\end{array}$ & .66 & .040 & $<.001$ & & & * \\
\hline & & & & & & & PM on SM & .10 & .010 & $<.001$ & .087 & .13 & * \\
\hline Between & & & & & & & Between & & & & & & \\
\hline Level & & & & & & & Level & & & & & & \\
\hline S on IU & -.005 & .002 & $<.001$ & -.008 & -.001 & * & S on IU & -.005 & .002 & $<.001$ & -.010 & -.001 & * \\
\hline Intercept & .24 & .060 & $<.001$ & .10 & .35 & * & Intercept & .17 & .076 & $<.001$ & .053 & .34 & * \\
\hline $\begin{array}{l}\text { Residual } \\
\text { Variance }\end{array}$ & .016 & .004 & $<.001$ & .011 & .026 & * & $\begin{array}{l}\text { Residual } \\
\text { Variance }\end{array}$ & .019 & .006 & $<.001$ & .013 & .034 & * \\
\hline
\end{tabular}

\subsubsection{IU as moderator of the search-presence relationship}

There was a significant effect of IU predicting the random slope of search to presence $(b=-.005$; Posterior SE $=.002$, BCI [-.008, -.001]), which suggests that those with higher levels of IU have a flatter slope of the search-presence relationship compared to those with lower levels of IU (see Figure 1a). In other words, the relationship between search and presence was stronger, or more positive, for low IU versus high IU people. 


\subsubsection{IU as moderator of the search_1-presence relationship}

There was a significant effect of IU predicting the random slope of search the day before (search_1) to presence $(b=-.005$; Posterior SE $=.002$, BCI [-.010, -.001]), corresponding to a flatter slope of the relationship between search_1-presence relationship among those with higher levels of IU compared to those with lower levels of IU (see Figure 1b). In other words, the relationship between searching for meaning the previous day and presence of meaning was stronger, or more positive, for low IU versus high IU people.

Figure 1a. IU as moderator of the same day search for meaning on presence of meaning relationship

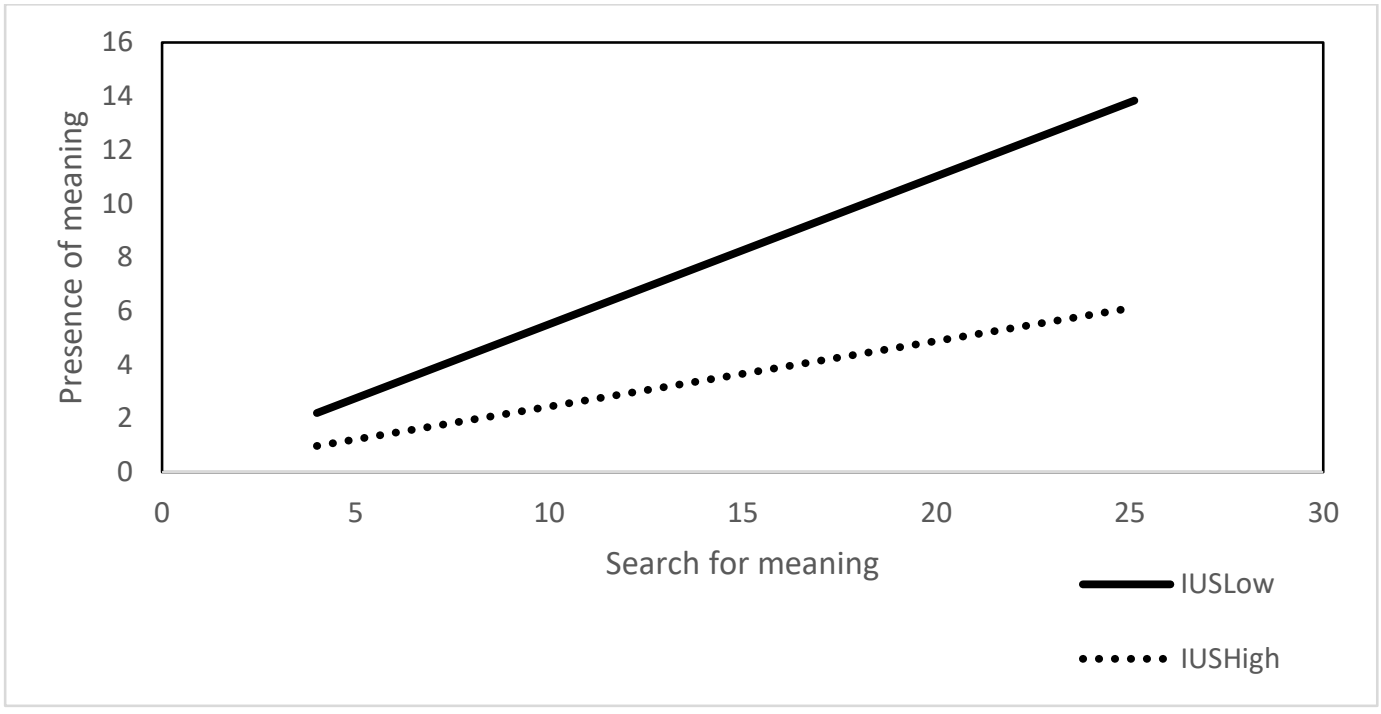

Figure $1 \mathrm{~b}$. IU as moderator of the prior day's search for meaning on current day's presence of meaning

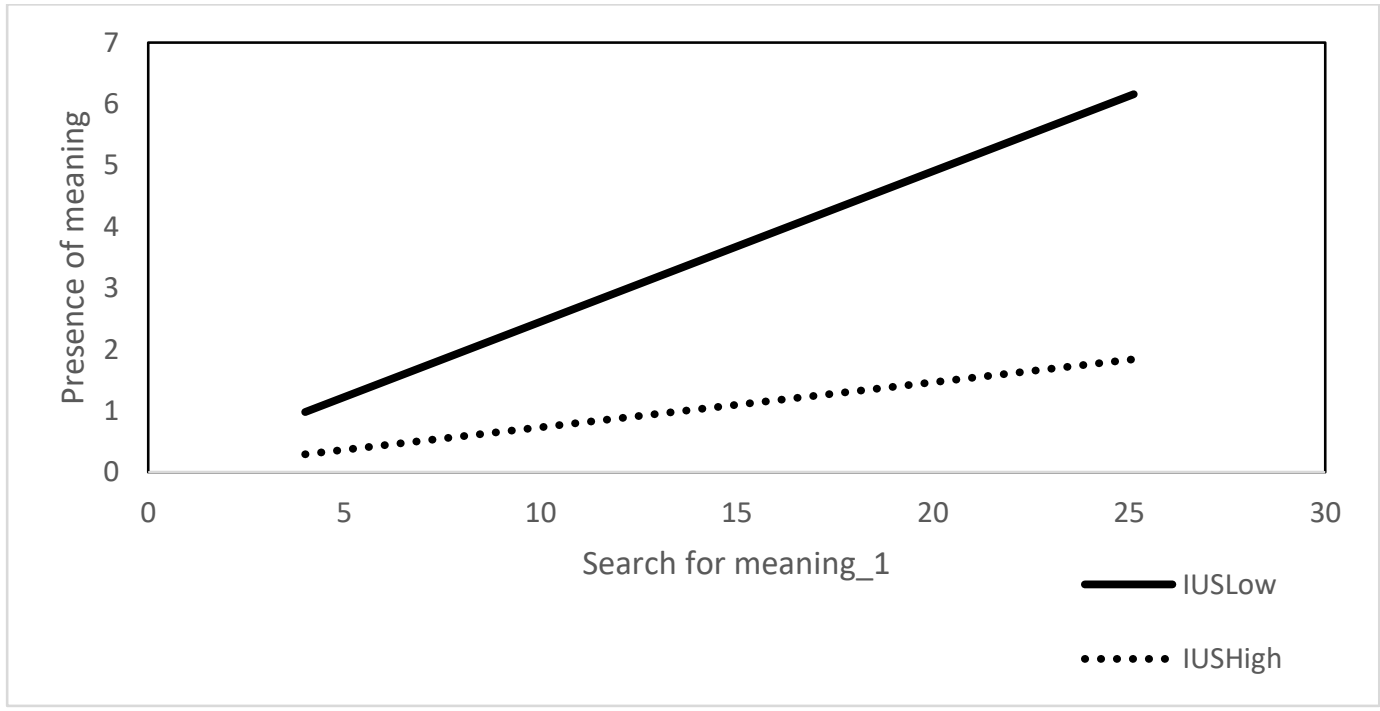

In addition to testing the overall IUS-12 score as a moderator, the prospective and inhibitory subscales of the IUS-12 were each tested as moderators of the same day and lagged day searchpresence relationships. Results of the moderation effects of both prospective and inhibitory IU converged with the moderation results from the total IU scale score, and thus are not presented. 


\subsection{Presence-search model (see Table 2)}

\subsubsection{Within-person effect of presence on search}

The random slope of daily presence predicting daily search was positive and statistically significant (SPresence-Search $=1.91$, Posterior SE $=.74$, Bayesian CI $[.35,3.45]$ ), indicating that on days participants reported a 1-unit increase in presence of meaning, they reported 1.91 more units of search for meaning.

\subsubsection{IU as moderator of the presence-search relationship}

There was not a significant effect of IU predicting the random slope of presence to search $(b=-$ .015; Posterior SE = .024, BCI [-.054, .033]). The lack of significant effect suggests that IU does not moderate the slope from presence to search.

\subsubsection{IU as moderator of the presence_1-search relationship}

There was not a significant effect of IU predicting the random slope of presence the day before to search $(b=-.003$; Posterior SE $=.031$, BCI $[-.076, .048])$, indicating no significant moderation by IU of the slope from presence the day before to search the following day, while controlling for presence.

The residual variances of the slope terms in all models were significant, which indicates that there is high variability across individuals in the slope between search and presence, with some individuals having a steeper slope (i.e., stronger relations) and others having a flatter slope (i.e., weaker relation) between search and presence on a given day.

The prospective and inhibitory subscales of the IUS-12 were also tested in separate models as moderators of the same day and lagged day presence-search relationships. Results of the moderation effects of both prospective and inhibitory IU converged with the moderation results from the total IU scale score, and thus are not included.

Table 2. 2 X (1-1) RCP method of IUS X (Presence-Search) and IUS X (Presence_1-Search) Moderated MSEM

\begin{tabular}{|c|c|c|c|c|c|c|c|c|c|c|c|c|c|}
\hline \multicolumn{7}{|c|}{ Presence-Search for meaning } & \multicolumn{7}{|c|}{ Presence_1 - Search for meaning } \\
\hline $\begin{array}{l}\text { Within } \\
\text { Level }\end{array}$ & Estimate & $S D$ & $p$ & $\begin{array}{l}95 \% \\
\text { Lower } \\
2.5 \%\end{array}$ & $\begin{array}{l}\text { C.I. } \\
\text { Upper } \\
2.5 \%\end{array}$ & Sig. & $\begin{array}{l}\text { Within } \\
\text { Level }\end{array}$ & Estimate & $S D$ & $p$ & $\begin{array}{l}95 \% \\
\text { Lower } \\
2.5 \%\end{array}$ & $\begin{array}{l}\text { C.I. } \\
\text { Upper } \\
2.5 \%\end{array}$ & Sig. \\
\hline $\begin{array}{l}\text { Intercept } \\
\text { Residual } \\
\text { Variance }\end{array}$ & $\begin{array}{l}10.21 \\
10.65\end{array}$ & $\begin{array}{l}.48 \\
, 51\end{array}$ & $\begin{array}{l}<.001 \\
<.001\end{array}$ & $\begin{array}{l}9.30 \\
9.81\end{array}$ & $\begin{array}{l}11.11 \\
11.82\end{array}$ & $\begin{array}{l}* \\
* \\
*\end{array}$ & $\begin{array}{l}\text { Intercept } \\
\text { Residual } \\
\text { Variance } \\
\text { SM on PM }\end{array}$ & $\begin{array}{l}8.28 \\
9.85 \\
\\
2.05\end{array}$ & $\begin{array}{l}.81 \\
.59 \\
\\
.16\end{array}$ & $\begin{array}{l}<.001 \\
<.001 \\
<.001\end{array}$ & $\begin{array}{l}6.71 \\
8.77 \\
\\
1.71\end{array}$ & $\begin{array}{l}9.67 \\
10.88 \\
2.38\end{array}$ & $\begin{array}{l}* \\
* \\
*\end{array}$ \\
\hline $\begin{array}{l}\text { Between } \\
\text { Level } \\
\text { S on IU } \\
\text { Intercept } \\
\text { Residual } \\
\text { Variance }\end{array}$ & $\begin{array}{l}-.015 \\
1.91 \\
2.42\end{array}$ & $\begin{array}{l}.024 \\
.74 \\
.50\end{array}$ & $\begin{array}{l}.27 \\
<.001 \\
<.001\end{array}$ & $\begin{array}{l}-.054 \\
.35 \\
1.82\end{array}$ & $\begin{array}{l}.033 \\
3.44 \\
3.60\end{array}$ & * & $\begin{array}{l}\text { Between } \\
\text { Level } \\
\text { S on IU } \\
\text { Intercept } \\
\text { Residual } \\
\text { Variance }\end{array}$ & $\begin{array}{l}-.003 \\
.13 \\
3.25\end{array}$ & $\begin{array}{l}.031 \\
1.01 \\
1.05\end{array}$ & $\begin{array}{l}.45 \\
.47 \\
<.001\end{array}$ & $\begin{array}{l}-.076 \\
-1.41 \\
1.84\end{array}$ & $\begin{array}{l}.048 \\
2.20 \\
5.78\end{array}$ & * \\
\hline
\end{tabular}

\section{Discussion}

The present study examined the relationship between daily search for and presence of meaning and considered the moderating effect of IU. Two conceptual models were tested, one hypothesizing that searching for meaning led to a greater chance of finding meaning, as 
operationalized by higher presence of meaning scores, and the second hypothesizing that losses in presence would result in compensatory searching for meaning. Results revealed support for the search-to-presence conceptual model. On days when people reported higher levels of searching, they also reported higher levels of presence, a pattern which held for same day and one-day lagged analyses. The results of this study align in part with theoretical assertions of MMM (Heine et al., 2006) and others (e.g., Park, 2010) in that people are able to restore or enhance their sense of meaning by searching for it.

This relationship between search and presence was significantly moderated by IU such that the relationship was more positive for low IU versus high IU people. In the lagged analysis model, searching the day before predicted higher levels of presence the following day and the relationship was stronger for people low in IU. Thus, people who are able to tolerate uncertainty find more meaning when they search than people who struggle to tolerate uncertainty. The relationship between searching for and experiencing presence of meaning is flatter for people who are highly intolerant of uncertainty. For high IU individuals, search processes may be tolerated with distress such that the translation of search to presence is compromised by discomfort or anxiety. High levels of IU may limit the amount of meaning people high in IU can experience. Perhaps, high IU individuals tend to operate at concrete, or lower levels of meaning making, as they attempt to assuage their distress, trying to find certainty as refuge. Thus, the meaning they find is not as "meaningful," which can explain why high IU people do not benefit as much from searching, in terms of presence of meaning. Alternatively, searching for meaning produces both meaning and anxiety for high IU people, and the perception or experience of anxiety dampens or distracts from experiencing presence of meaning. In summary, exploring existential questions inherent in searching for meaning might provoke feelings of uncertainty, which in those who tolerate uncertainty well leads to exploration, resulting in resolution. Among individuals high in IU, uncertainty likely induces anxiety along with limited exploration directed at finding certainty, which likely precludes experiencing more meaning in the aftermath of searching.

Results of the presence-to-search model was also significant. Interestingly, on days participants reported more presence of meaning, they reported heightened search for meaning. These results contradict the supposition of the presence-to-search model that a decrease in presence of meaning spurs searching for meaning as we observed an increase in presence of meaning prompted searching. Further, these effects were not significantly moderated by IU. Thus, when participants experienced more meaning on a day, they were more likely to search for meaning that same day and the next regardless of how they tolerate uncertainty. Presence of meaning may serve as a stable resource allowing for engagement in growth-oriented exploration, perhaps by searching for meaning. IU might not affect this relationship because the resource of presence of meaning provides people with stability and certainty, thus they seem not to be dissuaded from searching for meaning. At the trait level, Park and colleagues (2010) found that when people report high levels of search and presence, then search is associated with positive well-being outcomes rather than distress. Results at the daily level appear to converge such that people experience the benefits of stability and well-being in the context of presence of meaning, which then promotes exploration, self-actualization, and personal growth.

Results of lagged analyses indicate that presence of meaning significantly predicts searching for meaning the next day, but this relationship is not moderated by IU. Results of the directional model, although significant, does not lend support to the presence-to-search conceptual model, as deficits in presence of meaning did not ignite searching but rather increases in presence ignited search. It is not surprising that presence and search are significantly, positively correlated on a 
given day. On a day when someone feels that their life is meaningful, they may attend to or seek an understanding of the reasons that life feels meaningful that day and interpret such efforts as searching for meaning (Newman et al., 2017). However, a different process may be involved in the association between same day versus lagged search-presence. Disentangling these effects would require more nuanced assessments (e.g., qualitative interviews) aimed at better understanding participants' search for and presence of meaning.

Further, results of this study suggest that daily searching may not operate in the same way, or have the same consequences, as trait searching. In other words, someone who is searching for meaning on a particular day may not look the same as someone who is a perpetual "searcher". Consistent with previous studies (e.g., Steger et al., 2006), at the trait level, search and presence were weakly and negatively correlated in this study. At the daily level, search and presence were significantly positively correlated. Thus, daily search is positively related to daily presence; however, "searchers" are generally lower in presence of meaning. Additionally, at the trait-level, IU significantly negatively correlated with presence of meaning and was only slightly (nonsignificantly) negatively correlated with search. Thus, those with higher trait-level IU tended to report lower levels of presence and search, which may indicate that those who can better tolerate uncertainty are more likely to search for and perceive presence of meaning.

Overall, results of this study provide support for the search-to-presence conceptual model and suggest that when people who are highly intolerant of uncertainty search for meaning, they do not report finding or experiencing as much meaning that same day or the following day as those who are low in IU.

\section{Limitations and future directions}

There are a number of limitations to this study. Data was collected from a relatively small sample of primarily female undergraduate students. The search and presence of meaning profiles of young adults may differ from those of other ages. Some previous research suggests adolescents and young adults endorse searching for meaning at higher rates than other age groups (e.g., Bodner et al., 2014) and that search in young adulthood is not associated with the same levels of distress as typically noted (e.g., Steger et al., 2009). Thus, expanding this study to other age populations as well as more ethnically and culturally diverse populations is vital. Additionally, there was a significant percentage of missing data as many participants did not log in at the appropriate times, or at all, on days throughout the three-week time period. It could be that participants were less likely to log in on days when they were very busy, distressed, or elated, thus the data could be skewed. The use of self-reports and the length of the study may contribute to inaccurate reporting. Adding attention checks, varying the surveys given each day, and/or changing the length of the daily logs may improve the quality and response rate.

Examining lags across multiple days or examining dynamic change processes may also be informational. It is possible that we did not capture the true relationship between search and presence with the current design. A dynamic change model could inform if search or presence is a leading indicator of change or if true coupling between search and presence exists. Additionally, a potential implication of the research conducted here is that the process of converting search to presence may take longer or in some way "look different" for high IU individuals. Thus, examining trajectories of high IU versus low IU individuals may further elucidate the dynamics of converting search to presence.

\section{Conclusion}

Overall, these results highlight nuances in the dynamic processes of experiencing meaning, 
searching for meaning, and tolerating the uncertainty that comes with meaning making. Clearly, how people tolerate uncertainty plays an important role in the engagement in search processes and the translation from searching for meaning to experiencing it. When people search for meaning and do not find it, they are at higher risk for psychopathology and even suicidality (e.g., Yook et al., 2010). Thus, it is necessary for researchers to continue to examine the search-presence path for high IU people who are already at heightened risk for developing anxiety and depressive disorders due to their intolerance of uncertainty. Helping high IU individuals experience meaning in life and cope with the uncertainty that searching for meaning provokes may be vital, as presence of meaning provides people with a valuable buffer against the many stressors and uncertainties of daily life.

\section{Conflict of interest statement}

The authors declared no potential conflicts of interest with respect to the research, authorship, and/or publication of this article.

\section{Funding}

The authors received no financial support for the research, authorship, and/or publication of this article.

\section{Authors' Contributions}

Jessica L. Morse: Study conceptualization, investigation oversight, data curation, data interpretation, methodology, statistical analyses, and writing-original draft, writing-review and editing, approval of final draft.

Mark A. Prince: Data interpretation, methodology, statistical analyses, writing-review and editing, and approval of final draft.

Michael F. Steger: Study conceptualization, investigation oversight, writing-review and editing, approval of final draft.

\section{Authors}

Jessica L. Morse

Center for Meaning and Purpose, Department of Psychology, Colorado State University, Fort Collins, CO, USA

Phoenix VA Healthcare System

jessica.morse@colostate.edu

Mark A. Prince

Colorado State University

Michael F. Steger

Center for Meaning and Purpose, Department of Psychology, Colorado State University, Fort Collins, $\mathrm{CO}, \mathrm{USA}$

Optentia Research Programme, North-West University, Vanderbijlpark, South Africa

\section{Publishing Timeline}

Received 4 December 2019

Revised version received 25 January 2021

Accepted 26 January 2021

Published 31 January 2021 


\section{References}

Baumeister, R. F., \& Vohs, K. D. (2002). The pursuit of meaningfulness in life. In C. R. Snyder \& S. J. Lopez (Eds.), The handbook of positive psychology (pp. 608-618). New York: Oxford University Press.

Berenbaum, H., Bredemeier, K., \& Thompson, R. J. (2008). Intolerance of uncertainty: Exploring its dimensionality and associations with need for cognitive closure, psychopathology, and personality. Journal of Anxiety Disorders, 22(1), 117-125. https://doi.org/10.1016/j.janxdis.2007.01.004

Bodner, E., Bergman, Y. S., \& Cohen-Fridel, S. (2014). Do attachment styles affect the presence and search for meaning in life? Journal of Happiness Studies, 15(5), 1041-1059. https://doi.org/10.1007/s10902-0139462-7

Brosschot, J. F., Verkuil, B., \& Thayer, J. F. (2018). Generalized Unsafety Theory of Stress: Unsafe Environments and Conditions, and the Default Stress Response. International Journal of Environmental Research and Public Health, 15(3), 464-491. https://doi.org/10.3390/ijerph15030464

Buhr, K., \& Dugas, M. J. (2002). The intolerance of uncertainty scale: Psychometric properties of the English version. Behaviour Research and Therapy, 40(8), 931-945. https://doi.org/10.1016/S00057967(01)00092-4

Carleton, R. N. (2016). Into the Unknown: A review and synthesis of contemporary models involving uncertainty. Journal of Anxiety Disorders, 39, 30-43. https://doi.org/10.1016/j.janxdis.2016.02.007

Carleton, R. N. (2016). Fear of the unknown: One fear to rule them all? Journal of Anxiety Disorders, 41, 521. https://doi.org/10.1016/j.janxdis.2016.03.011

Carleton, R. N., Norton, M. P. J., \& Asmundson, G. J. (2007). Fearing the unknown: A short version of the Intolerance of Uncertainty Scale. Journal of Anxiety Disorders, 21(1), 105-117. https://doi.org/10.1016/j.janxdis.2006.03.014.

Cohen, K., \& Cairns, D. (2012). Is searching for meaning in life associated with reduced subjective wellbeing? Confirmation and possible moderators. Journal of Happiness Studies, 13(2), 313-331. https://doi.org/10.1007/s10902-011-9265-7

Dugas, M. J., Buhr, K., \& Ladouceur, R. (2004). The role of intolerance of uncertainty in etiology and maintenance. In R. G. Heimberg, C. L. Turk, \& D. S. Mennin (Eds.), Generalized anxiety disorder: Advances in research and practice. New York: Guilford Press.

Fergus, T. A., \& Rowatt, W. C. (2014). Intolerance of uncertainty and personality: Experiential permeability is associated with difficulties tolerating uncertainty. Personality and Individual Differences, 58, 128-131. https://doi.org/10.1016/j.paid.2013.10.017

Fourtounas, A., \& Thomas, S. J. (2016). Cognitive factors predicting checking, procrastination and other maladaptive behaviours: prospective versus inhibitory intolerance of uncertainty. Journal of Obsessive-Compulsive and Related Disorders, 9, 30-35. https://doi.org/10.1016/j.jocrd.2016.02.003

Frankl, V. E. (1963). Man's search for meaning: An introduction to logotherapy. Boston: Beacon Press.

Garrosa, E., Blanco-Donoso, L. M., Carmona-Cobo, I., \& Moreno-Jiménez, B. (2017). How do Curiosity, Meaning in Life, and Search for Meaning Predict College Students' Daily Emotional Exhaustion and Engagement? Journal of Happiness Studies, 18(1), 17-40. https://doi.org/10.1007/s10902-016-9715-3

Heine, S. J., Proulx, T., \& Vohs, K. D. (2006). The meaning maintenance model: On the coherence of social motivations. Personality and Social Psychology Review, 10(2), 88-110. https://doi.org/10.1207/s15327957pspr1002_1

Kashdan, T. B., \& Nezlek, J. B. (2012). Whether, when, and how is spirituality related to well- being? Moving beyond single occasion questionnaires to understanding daily process. Personality and Social Psychology Bulletin, 38 (11), 1523-1535. https://doi.org/10.1177/0146167212454549

Kashdan, T. B., \& Steger, M. F. (2006). Expanding the topography of social anxiety: An experiencesampling assessment of positive emotions, positive events, and emotion suppression. Psychological Science, 17(2), 120-128. https://doi.org/10.1111/j.1467-9280.2006.01674.x

Kashdan, T. B., \& Steger, M. F. (2007). Curiosity and pathways to well-being and meaning in life: Traits, states, and everyday behaviors. Motivation and Emotion, 31(3), 159-173.

https://doi.org/10.1007/s11031-007-9068-7

King, L. A., Hicks, J. A., Krull, J. L., \& Del Gaiso, A. K. (2006). Positive affect and the experience of 
meaning in life. Journal of Personality and Social Psychology, 90, 179-196. https://doi.org/10.1037/00223514.90.1.179

Machell, K. A., Kashdan, T. B., Short, J. L., \& Nezlek, J. B. (2015). Relationships between meaning in life, social and achievement events, and positive and negative affect in daily life. Journal of Personality, 83, 287-298. https://doi.org/10.1111/jopy.12103

Martela, F., \& Steger, M. F. (2016). The three meanings of meaning in life: Distinguishing coherence, purpose, and significance. The Journal of Positive Psychology, 11(5), 531-545. https://doi.org/10.1080/17439760.2015.1137623

Muthén, B., \& Asparouhov, T. (2003). Modeling interactions between latent and observed continuous variables using maximum-likelihood estimation in Mplus. Mplus Web Notes, 6, 1-9.

Newman, D. B., Nezlek, J. B., \& Thrash, T. M. (2017). The Dynamics of Searching for Meaning and Presence of Meaning in Daily Life. Journal of Personality, 86(3), 368-379. https://doi.org/10.1111/jopy.12321

Park, J., \& Baumeister, R. F. (2017). Meaning in life and adjustment to daily stressors. The Journal of Positive Psychology, 12(4), 333-341. https://doi.org/10.1080/17439760.2016.1209542

Park, C. L., \& Folkman, S. (1997). Meaning in the context of stress and coping. Review of General Psychology, 1(2), 115-144. https://doi.org/10.1037/1089-2680.1.2.115

Park, N., Park, M., \& Peterson, C. (2010). When is the search for meaning related to life satisfaction? Applied Psychology: Health and Well-Being, 2(1), 1-13. https://doi.org/10.1111/j.1758-0854.2009.01024.x

Peterson, C., Park, N., \& Seligman, M. E. P. (2005). Orientations to happiness and life satisfaction: The full life versus the empty life. Journal of Happiness Studies, 6(1), 25-41. https://doi.org/10.1007/s10902-0041278-z

Preacher, K. J., Zhang, Z., \& Zyphur, M. J. (2016). Multilevel structural equation models for assessing moderation within and across levels of analysis. Psychological Methods, 21(2), 189. https://doi.org/10.1037/met0000052

Preacher, K. J., Zyphur, M. J., \& Zhang, Z. (2010). A general multi- level SEM framework for assessing multilevel mediation. Psychological Methods, 15, 209-233. https://doi.org/10.1037/a0020141

Ryff, C. D. (1989). Happiness is everything, or is it? Explorations on the meaning of psychological wellbeing. Journal of Personality and Social Psychology, 57(6), 1069-1081. https://doi.org/10.1037/00223514.57.6.1069

Shihata, S., McEvoy, P., Mullan, B. A., \& Carleton, R. N. (2016). Intolerance of uncertainty in emotional Disorders: What uncertainties remain? Journal of Anxiety Disorders, 41, 115-124. https://doi.org/10.1016/j.janxdis.2016.05.001

Singer JD, Willett JB. (2003). Applied longitudinal data analysis: Modeling change and event occurrence. New York: Oxford University.

Starr, L. R., \& Davila, J. (2012). Temporal patterns of anxious and depressed mood in generalized anxiety disorder: A daily diary study. Behaviour Research and Therapy, 50(2), 131-141. https://doi.org/10.1016/j.brat.2011.11.005

Steger, M. F., \& Frazier, P. (2005). Meaning in life: One link in the chain from religiousness to well-being. Journal of Counseling Psychology, 52, 574-582. https://doi.org/10.1037/0022-0167.52.4.574

Steger, M. F., Frazier, P., Oishi, S., \& Kaler, M. (2006). The Meaning in Life Questionnaire: Assessing the presence of and search for meaning in life. Journal of Counseling Psychology, 53, 80-93. https://doi.org/10.1037/0022-0167.53.1.80

Steger, M. F., Kashdan, T. B., Sullivan, B. A., \& Lorentz, D. (2008). Understanding the search for meaning in life: Personality, cognitive style, and the dynamic between seeking and experiencing meaning. Journal of Personality, 76, 199-228. https://doi.org/10.1111/j.1467-6494.2007.00484.x

Steger, M.F., Morse, J.L., \& O’Donnell, M.B. (Unpublished, 2017). Seeking and Finding Meaning: A Review of Research on the Presence of Meaning and Search for Meaning Subscales of the Meaning in Life Questionnaire.

Steger, M. F., Oishi, S., \& Kashdan, T. B. (2009). Meaning in life across the life span: Levels and correlates of meaning in life from emerging adulthood to older adulthood. Journal of Positive Psychology, 4, 4352. https://doi.org/10.1080/17439760802303127 
van de Schoot, R., \& Depaoli, S. (2014). Bayesian analyses: Where to start and what to report. European Health Psychologist, 16(2), 75-84.

Walker, D. D., van Jaarsveld, D. D., \& Skarlicki, D. P. (2014). Exploring the effects of individual customer incivility encounters on employee incivility: The moderating roles of entity (in) civility and negative affectivity. Journal of Applied Psychology, 99(1), 151. https://doi.org/10.1037/a0034350

Yook, K., Kim, K. H., Suh, S. Y., \& Lee, K. S. (2010). Intolerance of uncertainty, worry, and rumination in major depressive disorder and generalized anxiety disorder. Journal of Anxiety Disorders, 24(6), 623628. https://doi.org/10.1016/j.janxdis.2010.04.003

Zika, S., \& Chamberlain, K. (1992). On the relation between meaning in life and psychological well-being. British Journal of Psychology, 83(1), 133-145. https://doi.org/10.1111/j.2044-8295.1992.tb02429.x 